\title{
Policing for impact
}

\section{Is South Africa ready for evidence-based policing?}

\section{Gareth Newham and Brian Rappert*}

gnewham@issafrica.org

b.rappert@ex.ac.uk

http://dx.doi.org/10.17159/2413-3108/2018/i64a2998

For decades, the prospect that research can improve the impact of policing operations and foster internal organisational efficiencies has been a source of promise and frustration. It may seem obvious to many that research should be able to assist with better policing strategies and tactics by providing evidence as to what does or does not work. Realising this potential, however, is not straightforward. This article reflects on evidence-based policing (EBP) and its challenges, as discussed at a workshop between the South African Police Service's first ever National Research Division, the Institute for Security Studies, and academic and policing organisations based in the United Kingdom.

In 2016 the South African Police Service (SAPS) took a bold step in establishing its first ever National Research Division, with the core objective of using research to improve policing in South Africa. While previously a senior officer had been responsible for processing research applications made to the SAPS, this was the first time that dedicated in-house research capacity was established.

It is not the first time that the SAPS has invested its resources in research as part of its efforts to improve internal efficiencies, or to develop policing strategies. The strategic management component of the SAPS has in the past commissioned or undertaken various research projects. These range from enabling more detailed insights into the types of crimes being recorded by the police, based on docket

\footnotetext{
* Gareth Newham is head of the Justice and Violence Prevention Programme at the Institute for Security Studies. Brian Rappert is a Professor of Science, Technology and Public Affairs in the Department of Sociology and Philosophy at the University of Exeter, UK.
}

analysis, to surveys aimed at assessing police service delivery at police stations. Other state agencies such as the national Civilian Secretariat of Police (CSP), some of the larger provincial police secretariats, organisations such as the Public Service Commission (PSC), the Human Sciences Research Council (HSRC) and the Centre for Scientific and Industrial Research (CSIR) have also commissioned or undertaken research on policing.

Moreover, there is a substantial amount of independent research in South Africa. There are a number of academic and research institutions with dedicated policing-focused components that have contributed to a considerable body of work. For example, between the years 2000 and 2012 there were around 500 academic articles published on policing in South Africa. ${ }^{1}$

Despite the large amount of research that has been undertaken, it is not clear how, or if, the findings are used and, if so, under what circumstances. There is also no dedicated 
multi-agency structure through which police officials can regularly engage with academics and other researchers about independent research that is underway and how it may be used effectively. It is also not clear that the research undertaken by the SAPS and some other state entities are subject to the rigours of peer review (as is standard for academic research).

According to the South African Police Service's research agenda for 2016 to 2020, the SAPS research component will be dedicated to the following objectives: ${ }^{2}$

- Ensuring institutionalisation and maintenance of research in the SAPS

- Commissioning high quality, independent, and relevant evidence-based research

- Directing and integrating research by, for and about the SAPS

- Influencing the South African policing agenda towards a common vision

- Supporting knowledge exchange between researchers and practitioners

- Improving the research evidence base for policing policy and practice

The research agenda is structured on four key pillars, ${ }^{3}$ which are presented as follows:

1. Enabling human resources for policing

2. Enabling assets for policing

3. Better service delivery

4. Building an ideal policing system

Across the four pillars, 18 themes have been formulated, each of which consists of a number of 'research priority areas'. In total there are almost 100 priority areas, many of which are highly ambitious in nature. For example, pillar 1 , theme 3 is stated as 'Moral regeneration in SAPS,' which consists of the following four research priority areas:
1. Redefining ethical SAPS sub-culture and rebuilding a culture of integrity in the SAPS, and documentation of SAPS sub-culture

2. Restoration of discipline in the SAPS and development of a strategy that will enhance discipline in the SAPS

3. Analysis of root causes of civil claims and their impact, and development of an integrated plan to reduce civil claims

4. Eradicating corruption within the service, and developing an anti-corruption strategy and incorporating it into the policing model to address corruption in law enforcement ${ }^{4}$

Given the breadth and depth of the agenda, the SAPS research division faces both high expectations and substantial challenges with regard to implementing its agenda. At the time of writing, the only official information on the work of the SAPS research component was contained in the SAPS annual report for the financial year 2016/17. ${ }^{5}$ This document states that towards the end of 2016, the division had held roundtable meetings in three provinces with the theme 'Towards the development of an ideal and suitable policing model for South Africa'. From 7 to 9 February 2017 a three-day research colloquium was held to introduce the division to various stakeholders. It also states that six research studies were conducted, five policing innovation hubs were held, five case studies were formulated for the Policing Centre of Excellence, and the SAPS Subject Matter Expert Concept and Validation Model was developed and approved by the National Management Forum (NMF). However, no additional details are provided on these achievements, for example, what the focus or outcomes of the six research studies were. These studies are also not published on the SAPS website, where information on the SAPS colloquium can be found. 
As a small contribution towards assisting the newly established SAPS research division in contextualising its work globally and broadening its international networks, the Institute for Security Studies (ISS) and the University of Exeter hosted a two-day workshop titled 'Enhancing Evidence-based Policing'. Held at the Pretoria headquarters of the ISS from 8-9 March 2017, the workshop brought together police officers from the Devon and Cornwall Police in the United Kingdom (UK), a representative of the College of Policing for England \& Wales, and academics from the University of Exeter, with the head of the SAPS research division, Lieutenant-General Dr Bongiwe Zulu, and seven of her senior police colleagues. The purpose of the workshop was to provide an opportunity for participants to reflect on their attempts to bring research into practice, to exchange information about current activities, as well as to identify barriers and facilitators for change.

This article will briefly explain the origins and evolution of evidence-based policing, before reflecting on the core issues discussed the workshop, ${ }^{6}$ and their implications for promoting evidence-based policing (EBP) in South Africa.

\section{What is evidence-based policing?}

A formal attempt to undertake research with the intention of improving policing strategies and tactics is not a recent idea. For example, in 1970, an independent non-profit organisation dedicated to advancing policing through innovation and science, called the Police Foundation, was established in the United States (US). ${ }^{7}$ It was responsible for some of the most famous policing experiments undertaken, such as the 'Kansas City Preventative Patrol Experiment'. Between 1972 and 1973, this experiment sought to test the hypothesis that the potential presence of visible police patrols would reduce crime. ${ }^{8}$ Interestingly, after assessing the impact of different frequencies of police patrols in three different geographical locations, it found that routine patrols in marked police cars did not result in lower crime rates or in increased feelings of safety in citizens. This led to the recommendation that random routine patrols could be abandoned for other tactics (for example, targeted patrols) without reducing the impact of policing on community safety. Nevertheless, despite such research findings, random patrols remain a common feature of policing activity around the world.

One of the leading promoters of the concept of EBP has been Lawrence W Sherman, who was the Police Foundation's director of research from 1979 to 1985 and is currently the director of the Institute of Criminology at the University of Cambridge. He was also one of the first academics to undertake a randomised controlled trial into the effects of police arrest on repeat offending. ${ }^{9}$ This trial found that arresting individuals suspected of committing domestic violence, as opposed to simply warning them, would reduce the chances that they would commit further violence. One of his later groundbreaking studies with criminologist David Weisburd in 1995 showed that focusing police resources on small geographical areas where reported crime is notably high (often referred to as crime 'hot spots') would significantly prevent crime from occurring at those locations. ${ }^{10}$ While these studies took place in particular locations (in the US) and may well not be generally applicable to all policing situations globally, they were good early examples of how scientific research methods could be applied to assess the impact of defined policing tactics in particular contexts.

The basic underlying imperative of EBP is that science can and should be used to drive improvements in the provision of public safety. Accordingly, Sherman argues that, 'in contrast to basing decisions on theory, assumptions, tradition, or convention, an evidence-based 
approach continuously tests hypotheses with empirical research findings'. ${ }^{11}$ Through this the hope is to improve the police's ability to enhance public safety and, in doing so, promote public confidence in policing.

From the late 1990s there were a number of attempts in the Western world to develop a clear list of programmes that prevent crime, based on scientific evidence. In 1996, a federal law was passed requiring the US Attorney General to provide Congress with an independent review of the effectiveness of crime prevention assistance programmes funded with public money. This resulted in Sherman being commissioned by the National Institute of Justice in the US Department of Justice to undertake a review of these programmes. Over 500 crime prevention programme evaluations that met specified minimum standards were reviewed, following which, Sherman and colleagues presented a report to Congress titled 'Preventing crime. What works, what doesn't, what's promising.'12 While the report managed to identify a number of programmes where evidence showed crime prevention initiatives to be effective, the number was too small for the establishment, at that time, of a clear provisional list of scientifically proven crime prevention programmes.

In 1998, Sherman published a paper titled 'Ideas in American policing: evidence-based policing', in which he defined evidence-based policing as 'the use of the best available research on the outcomes of police work to implement guidelines and evaluate agencies, units and officers'. ${ }^{13}$ The aim was for the police to be guided by evidence in order to ensure overall greater impact on their ability to promote public safety. In 2002, Sherman and colleagues published another book of the same name that reviewed over 600 crime prevention programmes (and was subsequently revised in 2006). ${ }^{14}$
Outside of the US, the evaluation of policing also has a long history in England and Wales. In the late 1990s, for instance, major initiatives such as the 'What works in crime reduction research?' programme, as well as the Home Office Closed Circuit Television Challenge, included evaluation requirements. The evaluations raised concerns about the management and delivery of these initiatives, the training of police personnel, and the importance of greater research collaboration with those outside the police. ${ }^{15}$ In recent years, however, there has been renewed effort directed at assessing and communicating effective police practice. The establishment of the College of Policing in 2012 as well as the 'What Works Centre for Crime Reduction' under the college in 2013 were in part justified as a way of drawing on expertise within the police and elsewhere to improve the identification, use, and undertaking of research that supports a reduction in crime.

This specific What Works Centre is one of seven such centres in the UK, each designed to improve decision-making across a wide range of public sector agencies by making them more evidence-based. ${ }^{16} \mathrm{~A}$ central task of the crime reduction centre is to discern what counts as methodologically rigorous knowledge to effect crime reduction. Its freely accessible Crime Reduction Toolkit, ${ }^{17}$ for instance, presents the outcomes of systematic reviews on topics associated with crime reduction in a userfriendly format.

Today, much of the international interest in promoting EBP is premised on the need not only for the greater utilisation of systematic research but also to promote new forms of collaboration. ${ }^{18}$ Indeed, EBP has grown internationally in the last two decades, following the establishment of the Society for Evidence Based Policing (SEBP) in the UK in 2010. ${ }^{19}$ Since then, similar SEBP associations have 
been opened in Australia, New Zealand, Canada and the US. International conferences are held at least annually with participants from all over the world attending. In recognition of the difficulties of integrating research into practice, the College of Policing's £10 million Police Knowledge Fund from 2015 to 2017 supported projects that were designed to encourage the utilisation of research in policing. ${ }^{20}$

While a bulk of EBP initiatives have largely taken place in Western developed countries, there appears to be growing interest in the developing world. A systematic review of police interventions aimed at reducing violence in developing countries identified 2765 records detailing policing interventions of some sort or another. ${ }^{21}$ With regard to interventions aimed specifically at interpersonal violence reduction, however, only 54 documents relating to 13 countries in Asia, Africa and Latin America were identified. Moreover, only five studies contained adequate details of sufficient methodological rigour to enable an assessment of the effectiveness of a particular intervention. An additional 37 studies were included that were of sufficient quality to enable an analysis of factors that contribute to the success or failure of policing interventions in developing countries.

This review is important for policymakers in the developing world, as it found, inter alia, that:

- Gender-based interventions can improve access to support services for female victims of violence if coupled with other social services and training.

- Well-articulated police-community partnerships with clearly defined and achievable goals, adequate resourcing and consistent personnel with good communication support are more likely to succeed.

- Training programmes to improve attitudes of police officers towards victims of violence are more likely to succeed if regular refresher courses are provided.

- Community-oriented policing interventions require proper community participation, political commitment, a multiagency approach and police cooperation. But if such programmes do not receive adequate funding and ongoing support, success is unlikely to be sustainable.

- Police crackdown and enforcement interventions aimed at tackling problems such as the illegal selling of alcohol and illegal possession of firearms can have a positive impact if there is sufficient political support and increased police visibility.

Nevertheless, despite the interest in the developing world for better evidence as to which policing interventions will have a desired impact, the level of investment and resourcing available for rigorous research studies appears to be far from adequate.

\section{What are the challenges to evidence- based policing?}

It is easy to make the assumption that once conclusive research findings are available on what may or may not work in policing, these will easily be incorporated into changes by a police agency. It quite quickly became clear to those at the forefront of EBP that this was generally not the case. Indeed, in his groundbreaking article on EBP as a new paradigm Sherman wrote that,

just doing research is not enough and [that] proactive efforts are required to push accumulated research evidence into practice through national and community guidelines. ${ }^{22}$

Experience to date would suggest that the mere existence of guidelines about how to use research is insufficient for police agencies to obtain the full benefits that research may have to offer. There are a number of reasons 
as to why this is the case. For example, police agencies that face funding cuts can turn toward EBP as a way of knowing with greater certainty whether the police are using their resources effectively. ${ }^{23}$ However, it may be the very same challenges with regard to funding and other resource-related limitations that stifle both the capacity to undertake research and the implementation of any new interventions based on the research findings. ${ }^{24}$

Despite long-standing efforts to promote $\mathrm{EBP},{ }^{25}$ many issues internal and external to the police have meant that much more could have been achieved than materialised in practice. ${ }^{26}$ Factors identified for the limited integration of research into police priorities and practice have related to organisational pressures (time, funding, shifting operational demands, political responsiveness), ${ }^{27}$ the characteristics of research (its costs, duration), policing culture, as well as the incompatibility between the police and external research organisations such as universities (in their agendas, standards, training, and forms of communication). ${ }^{28}$

Beyond such familiar constraints though, studies have suggested that some research findings can be regarded as uncomfortable or unwanted within the police. When research-based evidence is at odds with officers' experiential knowledge ${ }^{29}$ or with pre-existing professional cultures, ${ }^{30}$ it can be rejected or downplayed.

David Kennedy suggests that policing and criminal justice agencies routinely conduct themselves in ways known to be ineffective. ${ }^{31}$ He identifies a central reason for this situation, namely, that those in the criminal justice system perform roles rather than being driven by proven outcomes; a situation portrayed as at odds with professions such as medicine and engineering.

The effort to establish 'what works' in accordance with rigorous standards for evidence is not without its tensions. For instance, how (quasi-)experimental findings should relate to officers' professional experience of 'what works' or 'what matters' is an ongoing matter of debate internationally. ${ }^{32}$ Another challenge is the extent of rigorous causal research. The College of Policing's Crime Reduction Toolkit contains only 43 systematic reviews, which means that most of the major sways of policing policy (aimed at improving policing practices, tactics and strategies to address crime, uphold the rule of law and promote public safety) have been undertaken without the benefit of research findings to demonstrate or support that they will have the desired impact.

Moreover, as research techniques improve, initial findings on what works or not might change. For example, Sherman and Berk's field study (mentioned above) on the impact of arrests of police officers involved in domestic violence in the US found that arrested suspects were significantly less likely to commit violence again within six months of the arrest. ${ }^{33}$ However, later research found that the issue was more complex than initially thought in that 'the size of the reduction in repeat offending associated with arrest is modest compared with the effect of other factors (such as the batterer's age and prior criminal record) on the likelihood of repeat offending'. ${ }^{34}$ Moreover, this later study found that a majority of offenders stopped subsequent assaults after other forms of police intervention (such as through a warning or temporary separation), even if they were not arrested.

Still further challenges for EBP relate to addressing issues that are marginalised, not recognised, or otherwise off the radar. The crime of child sexual exploitation (CSE) ${ }^{35}$ in the UK is a salient example. Prior to a number of recent high-profile cases, little was systematically known about the extent of occurrence or the severity of harm of situations in which children are engaged in sexual relations in exchange for something they want or need. There was also little impetus to find out more about this 
specific type of child abuse. The age of some victims (legally able to give consent) and the appearance of consent in some cases were among the reasons why both those officers and others in the criminal justice system directly familiar with instances of CSE failed to respond to those cases with due regard. ${ }^{36}$ Today, in contrast, CSE has been elevated to the status of a national threat in the Strategic Policing Requirement and is meant to be a priority in every police force in the UK. ${ }^{37}$

The rise in prominence for CSE suggests the importance of questioning the assumptions and practices that delimit what is recognised as a salient issue for policing at any given time. One way to do this is by attending to how what is known becomes known. Within the topic of environmental protection, for instance, forceful arguments have been put forward for the need to devise novel forms of collaboration and consultation that go beyond traditional sciencebased methods for assessing hazards. ${ }^{38}$ By deliberately questioning assumptions, challenging vested agendas, and engaging with diverse stakeholder interests, it is possible to transform the ignorance of unknowns into something more tractable. Doing so requires raising questions about how the public at large and interested groups should shape research agendas.

\section{What are the opportunities for EBP in South Africa?}

When compared to the policing situation in the UK, it appears that South Africa has an important advantage. The UK consists of 43 police services, and therefore the governance of the police is highly devolved. This poses specific challenges in terms of the coordination and accessibility of policing research. While organisations such as the Home Office and the National Police Chiefs' Council undertake and coordinate research across forces, individual local forces working in partnership with the
Police \& Crime Commissioner largely set their own agendas based on locally orientated requirements. This results in the duplication of efforts, and hinders the ability to set a national agenda and strategically manage interventions based on research across forces. The devolved governance also requires compensatory activities to ensure research is widely shared. For instance, the College of Policing has established a voluntary research map of ongoing policingrelated research at Masters level and above to enable the exchange of information, facilitate networking, and reduce duplication. ${ }^{39}$

With the SAPS as a single national police agency, the situation in South Africa differs markedly. To date, the coordination of internal and external research has notably been limited. However, the creation of the South African Police Service's research agenda for 2016 to 2020 does provide a national elaboration of priorities. ${ }^{40}$ This was the result of commendable efforts taken within the SAPS to consult widely through open-ended questionnaires and unstructured interviews about which policing issues could be improved through research. It also serves as a framework for external researchers to contribute to policing knowledge. No such comprehensive mapping could be drawn for England and Wales today, given the devolved governance of police forces.

As noted above, with nearly 100 priority areas named, a pressing task in the SAPS now is to translate this listing into a sequential programme of impactful activities. A danger with the ambition of the current plan is that an absence of research across most of the 100 areas might result in criticism that the SAPS agenda is failing in some respects. On the other hand, undertaking action across all the areas runs the risk of diluting the available resources beyond the point at which meaningful change is possible.

Given the scale of the research agenda it is necessary for the SAPS to ensure that there 
is regular and consistent interaction with the various institutions involved in policing research in South Africa and beyond. This would better ensure that the SAPS does not duplicate efforts where research has already been undertaken, is underway or planned for the near future by external partners.

A good start was made early in 2017 with the SAPS National Research Division hosting a research colloquium so as to obtain presentations from a wide variety of partners on various aspects of the research agenda. ${ }^{41}$ Over a three-day period, 42 different presentations were delivered by both police officers and independent researchers on a multitude of topics of relevance for policing in South Africa. This set the scene for closer cooperation between the SAPS and the other institutions involved in policing research. A subsequent two-day symposium with the SAPS research division at the end of June 2017, titled 'Moving Towards International Crime Recording Standards through Purified and Standardised Crime Statistics', provided further opportunities for cross-sectoral engagement on police data and how it could be improved and better used.

These events herald a welcome shift towards greater engagement and collaboration with partners external to the police on research and data. However, the events consisted of hundreds of participants engaging in either a single plenary or big breakaway groups. The challenge is now to start developing closer and ongoing relationships between the SAPS research division and research partners on specific projects. This could be achieved by the SAPS presenting its immediate research priorities and hosting a meeting for those who are directly involved or have expertise in the areas prioritised. Smaller and more regular engagement on particular topics could further enable the development of dedicated research partnerships that could better enrich SAPS exposure to new knowledge and interventions.

It is also important to establish a clear set of standards against which research can be assessed and accepted by the SAPS. While there may be a lot of research taking place, it is critical that results are subject to appropriate standards of review before being utilised by the SAPS to inform operations and other interventions. This highlights another challenge that the SAPS research division may face: ensuring that it is able to influence policing practice across its various programmes, including administration, visible policing, detective services, crime intelligence and VIP protection services. Careful consideration will have to be given as to how the SAPS national management forum could be used to promote the use of evidence in the development of strategic and annual plans, as well as specific interventions for an organisation consisting of around 194000 employees.

In addition to developing local research partnerships, the SAPS research division should consider tapping into the rich international experience in EBP. During the workshop with the University of Exeter, police officers and a representative from the College of Policing in the UK, participants discussed how this could be achieved. A key option would be for South Africa to establish a Society of Evidence Based Policing (SEBP), which would enable it to formally engage with research developments in policing from other parts of the world. South Africa would also be in a good position to assess policing in a context that could be of interest and use across the continent. Bringing an African perspective could enrich international debates on and insights into policing, particularly from a developing country viewpoint. Ideally, the SAPS research division would be part of driving this initiative, along with key South African institutions involved in 
policing research. This would provide a

formal, more structured platform for policing research in South Africa to be profiled not only nationally but also across the African continent and beyond.

\section{Research funding}

Funding for the 'Enhancing Evidence-based Policing' workshop was provided, in part, by the Economic and Social Research Council IAA Award, titled 'Enhancing Evidence-Based Policing: Promoting UK-South Africa Dialogue'.

To comment on this article visit

http://www.issafrica.org/sacq.php

\section{Notes}

1 JP Banchani and E van der Spuy, Bibliography on police and policing research in South Africa, 2000-2012, Centre of Criminology, Faculty of Law, University of Cape Town, 2013.

2 South African Police Service (SAPS), Division Research, South African Police Service's research agenda for 2016 to 2020, Pretoria: SAPS, 2016.

3 Ibid., 8.

4 This text has been slightly adapted from the original, which was quoted verbatim.

5 SAPS, Annual report 2016/2017, Pretoria: SAPS, 2017, 83-84.

6 While this article is informed by the workshop, the arguments forwarded are those of the authors only.

7 For the history of the Police Foundation, see Police Foundation, History of the Police Foundation, https://www. policefoundation.org/about/history/ (accessed 3 August 2017).

8 G Kelling et al., The Kansas City preventive patrol experiment: a technical report, Washington DC: Police Foundation, 1974.

9 LW Sherman and R Berk, The specific deterrent effects of arrest for spouse assault: a field experiment, American Sociological Review, 49:2, 1984, 261-272.

10 LW Sherman and D Weisburd, General deterrent effects of police patrol in crime 'hot spots': a randomized study, Justice Quarterly, 12:4, 1995, 625-648.

11 LW Sherman, The rise of evidence-based policing: targeting, testing and tracking, Crime and Justice, 42:1, 2013, http:// cebcp.org/wp-content/evidence-based-policing/ShermanTripleT.pdf (accessed 3 August 2017).

12 LW Sherman et al., Preventing crime. What works, what doesn't, what's promising, National Institute of Justice, July 1998, https://www.ncjrs.gov/pdffiles/171676.pdf (accessed 6 June 2018).

13 LW Sherman, Ideas in American policing: evidence-based policing, Washington DC: Police Foundation, 1998, 2, https:// www.policefoundation.org/wp.../Sherman-1998-EvidenceBased-Policing.pdf (accessed 23 March 2017). Also see the College of Policing's definition at What Works, What is evidence-based policing?, http://whatworks.college.police.uk/ About/Pages/What-is-EBP.aspx (accessed 23 March 2017).

14 LW Sherman et al. (eds), Evidence-based crime prevention, London: Harwood Academic Publishers, 2002.
$15 \mathrm{~K}$ Bullock and N Tilley (eds), Crime reduction and problemoriented policing, Cullompton: Willan, 2003.

16 For background on the reasoning for the centres, see G Mulgan and R Puttick, Making evidence useful: the case for new institutions, London: Nesta, 2013.

17 What Works, Crime reduction toolkit, http://whatworks.college. police.uk/toolkit/Pages/Toolkit.aspx (accessed 6 June 2018).

18 D Bradley and C Nixon, Ending the 'dialogue of the deaf': evidence and policing policies and practices, an Australian case study, Police Practice and Research, 10:5-6, 2009, 423-435.

19 Society of Evidence Based Policing, Australia and New Zealand SEBP, https://www.sebp.police.uk/australia (accessed 4 August 2017).

20 The Police Knowledge Fund is a collaborative initiative between the College of Policing, the Higher Education Funding Council for England and the Home Office. See What Works, Police Knowledge Fund, http://whatworks.college.police.uk/ Partnerships/Knowledge-Fund/Pages/Police-Knowledge-Fund. aspx (accessed 6 June 2018).

21 A Higginson et al., Policing interventions for targeting interpersonal violence in developing countries: a systematic review, Grantee Final Review, International Initiative for Impact Evaluation (3ie), August 2015, http://www.3ieimpact.org/media/ filer_public/2015/10/01/policing_interventions_review.pdf (accessed 21 April 2018).

22 Sherman, Ideas in American policing, 1.

$23 \mathrm{~J}$ Bueerman, Being smart on crime with evidence-based policing, National Justice Institute Journal, 269, March 2012, https://www.nij.gov/journals/269/pages/evidence.aspx (accessed 3 August 2012).

24 JC Fell, JH Lacey and RB Voas, Sobriety checkpoints: evidence of effectiveness is strong, but use is limited, Traffic Injury Prevention, 5:3, 2004, 220-227.

25 For a historical review centred on the US, see J Rojek, G Alpert and $\mathrm{H}$ Smith, The utilization of research by the police, Police Practice and Research, 13:4, 2012, 329-341.

26 D Weisburd and P Neyroud, Police science: toward a new paradigm, Cambridge, MA: Harvard University, 2011.

27 See, for instance, P Beal and R Gil Kerlikowske, Action research in Buffalo and Seattle, Police Practice and Research, 11:2, 2010, 117-121.

28 CW Telep and C Lum, The receptivity of officers to empirical research and evidence-based policing: an examination of survey data from three agencies, Police Quarterly, 17, 2014, 359-385.

29 Ibid.

30 L Carson and D Rooy, 'Commonsense psychology' is a barrier to the implementation of best practice child interviewing guidelines: a qualitative analysis of police officers' beliefs in Scotland, Journal of Police and Criminal Psychology, 30:1, 2015, 50-62.

31 D Kennedy, Hope and despair, Police Practice and Research, 11:2, 2010, 166-170.

32 Telep and Lum, The receptivity of officers to empirical research and evidence-based policing; P Ekblom, From the source to the mainstream is uphill, in N Tilley (ed.), Analysis for crime prevention, London: Sage, 2002, 131-203.

33 Sherman and Berk, The specific deterrent effects of arrest for spouse assault.

34 CD Maxwell, JH Garner and JA Fagan, The effects of arrest on intimate partner violence: new evidence from the spouse assault replication program, National Institute of Justice, 2001, https:// www.ncjrs.gov/pdffiles1/nij/188199.pdf (accessed 6 June 2018).

35 According to the 2017 revised definition by the Department for Education, CSE 'is a form of child sexual abuse. It occurs 
where an individual or group takes advantage of an imbalance of power to coerce, manipulate or deceive a child or young person under the age of 18 into sexual activity (a) in exchange for something the victim needs or wants, and/or (b) for the financial advantage or increased status of the perpetrator or facilitator. The victim may have been sexually exploited even if the sexual activity appears consensual. Child sexual exploitation does not always involve physical contact; it can also occur through the use of technology.' See Research in Practice, Government releases new definition and guide for child exploitation, 17 February 2017, https://www.rip.org. uk/news-and-views/latest-news/government-releases-newdefinition-and-guide-for-child-exploitation/ (accessed 6 June 2018).

36 A Jay, Independent inquiry into child sexual exploitation in Rotherham 1997-2013, Rotherham: Rotherham Borough Council, 2014; C Fox, It's not on the radar, Barkingside: Barnardo's, 2016.

37 British Government, Tackling child sexual exploitation, London: Cabinet Office, March 2015

38 A Stirling, Science, precaution, and the politics of technological risk, Ann. N.Y. Acad. Sci., 1128, 2008, 95-110.

39 What Works, Policing and crime reduction research map, http://whatworks.college.police.uk/Research/Research-Map/ Pages/Research-Map.aspx (accessed 6 June 2018).

40 SAPS, Division Research, South African Police Service's research agenda for 2016 to 2020, 8.

41 The event titled 'Research Colloquium: Towards an Ideal and Suitable Policing Model for the SAPS' was held from 7-9 February 2017 at the CSIR International Conference Centre, Pretoria. See SAPS, Research colloquium, https://www.saps. gov.za/resource_centre/publications/research_colloquium.php (accessed 3 August 2017). 